\title{
TURNING DATA INTO VALUABLE INSIGHTS: THE CASE STUDY IN AVIATION SECTOR COMPANY
}

\author{
Daiga Ergle, ${ }^{1}$ Iveta Ludviga, ${ }^{2}$ Agita Kalvinga ${ }^{3}$
}

\begin{abstract}
Since the early 2000s, there is increasing pressure on Human Resource Departments to show their impact on organizational performance. This pressure is related to the shift from industrial based economies to knowledge based economies and positioning people as potential sources of competitive advantage, and to the rise of Evidence-Based Management (EBM), which requires making decisions based on data and analysis. New technologies have enabled HR departments to start a transition from HR metrics to HR Analytics, thus transforming from the traditional administrative HR function to a more strategic HR function that can express qualitative matters and its impact on organizational performance with numbers. This case study describes the implementation of HR analytics in an aviation sector company. Quantitative data gathered from an annual staff engagement survey are analyzed using a Structural Equation Modelling technique with Smart PLS software. The results show that the analysis offers insights which are much more valuable than traditional diagnosis of the level of employee engagement. Thus, management can trace an employee's journey within the organization and be able to predict their behavior in relationship to the time spent in the organization. Moreover, the changing needs of employees are seen form the analysis and Evidence-Based Management can be implemented.
\end{abstract}

JEL Classification Numbers: M1; M50; M54: M51; DOI: http://dx.doi.org/10.12955/cbup.v5.941

Keywords: Human Resource analytics, employee engagement, structural equation modelling, evidence based management

\section{Introduction}

Over the past three decades many researchers have tried to prove Human Recourse's (HR) impact on business by unraveling the link between HR and individual and organizational performance (Evans \& Davis, 2005; Fitz-Enz, 1984; Huselid, 1995; Paauwe et al., 2012). However, still a lot of questions regarding the link between HR and organizational performance remain unanswered (Paauwe et al., 2012) and there is still a lot unknown. In the early 2000s, the pressure on HR to be able to show its impact was increasing. On the one hand, this pressure was caused due to the shift from industrial based economies to knowledge based economies. This shift positioned people as valuable assets within the organization that play an important role in gaining competitive advantage (Pease et al., 2014). Knowing how HR impacts organizational performance therefore became more important as it could help to create competitive advantage. On the other hand, it was a result of the rise of Evidence-Based Management (EBM), which requires making decisions based on data and analysis (Fink, 2010; Rynes et al., 2007). As the opportunities to collect and use huge amounts of data increased over the last decade due to new, fast and relatively cheap technologies, the ability to make better data based decisions grew (Russel \& Bennet, 2015). Many organisational functions, such as finance and marketing, nowadays conduct EBM and have successfully adjusted themselves to make data based and analytic decisions to justify their activities (Boudreau \& Ramstad, 2005; Lawler et al., 2004; Rynes et al., 2007). However, in most organizations HR still relies on gut-based decisions (Mishra et al., 2016). As a result, investments in HR cannot be justified due to a lack of available data and it is not possible to quantify the returns on investments (Mondore et al., 2011). It is likely that HR will be able to implement EBM within the next decade. New technologies developed during the 2000s have enabled HR to start a transformation from HR metrics to HR Analytics (Bassi, 2011).

This paper presents a case study of an aviation sector company and describes the value of the implementation of HR analytics by presenting predictive analytics of available HR metrics. The paper is structured as follows: first HR metrics and HR analytics are defined and the transition discussed. Further the methodology is presented, followed by analysis of the company`s HR data and findings. From HR metrics to HR analytics

In the early 1970s, HR metrics were established by HR practitioners and researchers as a first attempt to quantify HR activities (Bassi, 2011; Fitz-enz, 2010). HR metrics are measurable units describing the personnel related characteristics of an organization, traditional examples are retention rate, turnover rate and cost of hire (Bassi, 2011; Fitz-enz, 2010; Fitz-enz \& Mattox, 2014). In the 1980s and 1990s

\footnotetext{
${ }^{1} \mathrm{PhD}$ student, University of Latvia, daiga.ergle@airbaltic.lv

${ }^{2}$ Dr.sc.administr., assoc.prof., RISEBA University, iveta.ludviga@ riseba.lv

${ }^{3}$ PhD student, RISEBA University, agita.kalvina@ riseba.lv
} 
the established HR metrics were further developed and new HR metrics were created (Fitz-enz, 2010) enabling organizations to conduct benchmarks with other organizations using HR metrics (Bassi, 2011), which marks the first step towards the ability of HR to show its impact on organizational performance.

HR analytics is defined as "the application of a methodology and integrated process for improving the quality of people-related decisions for improving individual and/or organizational performance" (Bassi, 2011, p. 16). Applying HR Analytics goes beyond using HR metrics (Fitz-enz \& Mattox, 2014). HR metrics merely describe personnel related characteristics of an organization in numbers. HR Analytics goes one step further by trying to understand relations and interactions between personnel related characteristics of an organization (Fitz-enz \& Mattox, 2014). The transition of the use of HR metrics towards HR Analytics is seen as the beginning of an evolution of the HR function (Fitz-enz, 2010; Van den Heuvel \& Bondarouk, 2016). This evolution entails a transformation from the traditional administrative HR function to a more strategic HR function that is able to show impact on organizational performance with numbers (Fitz-enz, 2010). HR Analytics is seen as an HR tool for conducting Evidence Based Management (EBM) (Falletta, 2014; Fitz-enz \& Mattox, 2014; Mondore et al., 2011).

Effectively conducting HR Analytics means showing HR's impact on business results (Mondore et al., 2011). This is experienced as a struggle by many starters in HR Analytics as a clear purpose for HR Analytics is often missing (Fitz-enz \& Mattox, 2014). As a result, HR practitioners report on analyses that are not perceived to be relevant for business (Mondore et al., 2011). For example, only reporting on the time it takes to hire a new employee is not relevant for the CEO as it does not show the impact on organizational performance. The purpose of HR Analytics should be linked to the HR strategy as the HR strategy determines the kind of investments and decisions HR makes with regards to the workforce (Pease et al., 2014). Aligning the purpose of HR Analytics with the HR strategy should lead to alignment of HR Analytics with organizational goals as the HR strategy should be based upon the organizational strategy.

When the purpose of HR Analytics is clear, HR Analytics can be used to solve business cases. By using HR Analytics on a particular business case, HR practitioners can figure out how HR activities support improving business results by improving business decisions (Fitz-enz \& Mattox, 2014). The purpose of a specific business case forces HR practitioners to focus on particular data sets, which helps to overcome data abundance and focussing on HR activities that impact organizational development. As HR Analytics combines HR and business data, it is relevant to thoroughly understand the business in which the organization is operating to be able to select relevant HR and business data (Fitz-enz, 2010; Pease et al., 2014; Rasmussen \& Ulrich, 2015). Understanding the business will give insight in the critical outcomes of organizations and the problems that organizations are facing (Gardner et al., 2011; Mondore et al., 2011). Furthermore, it will teach HR practitioners to speak the language of the business (Fitz-enz \& Mattox, 2014; Pease et al., 2014).

Since HR Analytics is a new HR tool, only a few organizations have so far succeeded in implementing and using HR Analytics. Many HR practitioners are struggling with HR Analytics as it is difficult to have the right competences and available resources and thereby, HR Analytics should be specifically tailored to the organization (Bassi, 2011; Lawler et al., 2004; Van den Heuvel \& Bondarouk, 2016). Since researchers have only recently focused their attention on HR Analytics, there is not much academic literature available yet (Fink, 2010; Van den Heuvel \& Bondarouk, 2016). Therefore, HR practitioners who want to conduct HR Analytics are highly dependent on success stories, recommended action plans and advises of HR practitioners that have already implemented HR Analytics within their organizations (Fitz-enz, 2010; Fitz-enz \& Mattox, 2014; Pease et al., 2014). Comparing the current literature regarding HR Analytics, five questions can be constructed on how to approach HR Analytics. Those five questions are: What is the purpose? What data is available? How is the data structured? What kind of analysis is needed? How can the outcome of the analysis be used?

\section{Methodology}

The company analyzed in this research paper operates in the aviation industry and has recovered from a financial setback in 2011. During the financial setback, the organization suffered cutbacks and 
reorganizations, which also influenced the position and the budget of the HR department. Now the organization is doing better, the HR department envisions a more strategic position for itself. However, the HR department has difficulties building credibility and persuasion power. Consequently, they are not yet able to convince the board and other business executives of their position as a strategic partner and they don't know how to show their impact on business results. As HR Analytics is referred to as a tool to build credibility of HR and persuasion power by proving the impact of HR on business, the HR department wants to implement HR Analytics within company.

This research starts with assessing the current data capability with regards to HR Analytics. In order to capture the underlying beliefs and understandings of the HR strategy, policies and practices and thoroughly understand the aviation industry, this research starts with a qualitative approach - semistructured interviews which enable the interviewer to ask follow-up questions if needed to gain a better understanding of the answers given by respondents (Verschuren \& Doorewaard, 2010). In total 12 semi-structured interviews are conducted. The interviews with HR practitioners had a duration of 90 minutes and the interviews with business executives were approximately 60 minutes. The HR practitioners provided an insight into the HR strategy, policies, practices and the daily tasks of HR practitioners, which gave insight into the purpose of implementing HR Analytics and the available data. The business executives gave insight in the aviation industry and in business needs. All interviews were recorded and transcribed verbatim to be able to analyze them and construct key word takeaways. In addition, this research used document analysis to figure out what data is available and to analyze the data structure. For the document analysis, HR policy documents, HR documents and notifications on intranet and excel files with collected HR data were used, which were created between 2011 and 2016 by HR practitioners.

The final stage of this research is quantitative - existing data from an annual employee commitment survey was analyzed using a structural equation modelling technique and Smart PLS software thus showing the value of predictive analytics. This research can be classified as an evaluative case study. Through case studies, the researcher aims to interpret the data, moreover, in evaluative case studies, the researcher goes further by adding their judgment to the phenomena found in the data (Zainal, 2007).

\section{Findings}

The results of the interviews with the HR department revealed that the recruitment and selection process is the main responsibility of human resources. For some positions, this process is more challenging as the Latvian labor market is shrinking which is enforced by the low wages compared to other countries. Interviews with the business show that their decisions are limited by the international regulations of the aviation industry. Since strategic decisions can only be taken by higher management, employees need to follow the hierarchical chain via the direct manager. Furthermore, interviewees from the business explain that HR only supports them in the recruitment \& selection process. They also mention the benefits from having a database in which language capabilities and trainings would be accessible by managers, as currently HR data cannot be easily found. Yet, investments in better systems are often postponed due to budgets.

Looking at the available HR data, it is evident that the company is currently doing basically descriptive analytics. For example, based on the sickness rate of cabin crew, it can describe trends regarding absence due to sickness for this specific employee group. Furthermore, some diagnostic analytics can be conducted on HR data, such as the Commitment Survey results and the results of the Annual Performance Review Dialogue. However, solely using HR metrics for descriptive and diagnostic analytics would not be sufficient for the evolvement of a strategic partner, because these types of analytics give only insights in the past. To support HR as a strategic partner, HR Analytics should provide predictions about the future that can help HR to formulate and execute adequate HR strategy and make evidence-based decisions (Fitz-enz \& Mattox, 2014). The type of analytics that would be suitable for the HR department to grow into the position of strategic partner is predictive analytics. Therefore, further an attempt to analyze existing data from annual commitment survey with SmartPLS software and thus provide the company with much more valuable insights is presented. 


\section{Implementation of HR Analytics}

In the company employee commitment and engagement is measured on a yearly basis using an external consulting company and multiple recommendations for increasing the commitment are provided. However, actions based on these recommendations have not been effective in the past. Since 2012, employee commitment is significantly underneath Latvia's benchmark. Over the years, there has not been any real indication of improvement in employee commitment.

The data of the Employee Commitment survey is gathered on an individual but anonymous level via a self-reporting questionnaire using a 5-point Likert type measurement scale, where code 1 is assigned to "Not at all satisfied," and 5 is assigned to "Extremely satisfied." The questionnaire includes the scales measuring employee engagement (ENG, 8 items) and commitment (COM, 3 items), and employee satisfaction with general management (Man, 5 statements), company in general (Comp, 5 items), team (Team, 5 items), direct management (DirMan, 6 statements), remuneration (Rem, 5 items), growth possibilities (Grow, 3 items), availability of information (Inf, 5 items). In addition, demographic type questions like tenure and department are included.

In total 640 employees participated in the survey in 2016. The overall commitment of employees is identified as 55 points out of 100. Although this is an average commitment score following the methodology, it is underneath the benchmark of Latvia, the Baltic States, Europe and other service providers in Europe. The lowest commitment score is obtained by the cabin crew department, with 44 points out of 100. The highest commitment score is obtained by the administration and support department, with 63 points out of 100. Although almost all commitment scores among departments are either stable or slightly increasing, the commitment scores of the cabin crew show a negative trend. Furthermore, a difference is noticeable between employees that are less than one year working in the company, with a commitment score of 78 out of 100, and employees that are working for 6 to 10 years, with a commitment score of 47.

To identify causal relations, a Structural Equation Modelling (SEM) technique is used to test how management, team, growth, company, information, remuneration and direct management is linked to engagement and commitment. SEM is a statistical method for representing and testing a network of relations between observed and latent variables (Suhr, 2006).

First the validity of the model was tested. To evaluate reflectively measured models the following should be examined: outer loadings (size and significance); composite reliability; average variance extracted (AVE) or convergent validity; discriminant validity (Hair et al., 2011). All outer model loadings, except two, had a loading higher than .70, which indicates that they are good measurements of the latent variables. However, as the two indicators match with the Gallup model of engagement and the indicators have a .85 Cronbach's alpha, this research does not exclude the indicators from the model. Convergent Validity of the reflective constructs is examined with average communality or Average variance extracted (AVE). All scores were above the minimum threshold which is .50 (scores were between .55 for Rem and .77 for Grow). Internal consistency reliability is estimated by composite reliability (scores are from .086 Rem to .95 DirMan) and all scores exceed the minimum level of .70. Discriminant validity shows if measures of a particular construct differ from measures of other constructs in the model. The Heterotrait-Monotrait (HTMT) ratio of correlation was used and the values ranged from .37 to .78 , thus, the discriminant validity is sufficient since all scores are above .85. All collinearity statistics scored lower than 5, which indicate that the model has no problems with collinearity. Thus, the model appeared to be valid for further analysis.

The predicting capacity of the model is evaluated by determination coefficients. As the R2 for ENG is .63 , the model has a rather substantial predicting capacity for engagement. The R2 value for COM .38 indicates a predicting capacity of the model which is rather moderate for commitment. Since engagement can be predicted for $63 \%$ via the HR related scales, and engagement can predict commitment for $38 \%$; the model has substantial predicting capacity.

First the general model is analyzed. The path coefficients show a strong relationship between engagement and commitment. Information has the biggest impact on the engagement of employees, then team, company, remuneration and growth. However, to identify the cause of low commitment of specific groups, multigroup analysis is required. Descriptive analytics showed large differences 
between employees with different years of working experience within the company. These differences are further examined via a multi group analysis and presented in Table 1.

\begin{tabular}{|l|l|l|c|c|c|}
\hline Table 1: Multigroup analysis: Tenure (dependent variable - Engagement) \\
\hline Tenure (years) & Less than 1 & 1 to 3 & 4 to 5 & 6 - 10 & More than 10 \\
\hline & $\mathrm{n}=63$ & $\mathrm{n}=210$ & $\mathrm{n}=75$ & $\mathrm{n}=163$ & $\mathrm{n}=99$ \\
\hline Company in general (Comp) & .07 & $.31 * * *$ & -.02 & 0.3 & 0.25 \\
\hline Direct management (DirMan) & -.01 & .06 & .06 & .11 & .04 \\
\hline Growth (Grow) & .00 & .03 & $.28 *$ & $.17 *$ & -.01 \\
\hline Information (Inf) & $.50^{*}$ & $.24 * *$ & .21 & $.40^{* * *}$ & .23 \\
\hline Management (man) & .12 & .00 & .17 & .03 & -.06 \\
\hline Remuneration (Rem) & .08 & .07 & .16 & $.20^{* *}$ & .08 \\
\hline Team (Team) & .24 & $.31 * * *$ & $.38^{* * *}$ & $.13^{*}$ & $.28^{* * *}$ \\
\hline $\mathrm{p}<.05 ; * * \mathrm{p}<.01 ; * * * \mathrm{p}<.001$. & & & & \\
\hline Source: Authors &
\end{tabular}

The Table 1 shows that depending on the stage of the employees' journey in the organization, distinct factors become relevant for their engagement. When an employee just joined the organization, information is the only and most important factor relating to the engagement of employees. Throughout the journey of an employee in the company, information remains one of the predicting factors for the engagement. When an employee is between 1 to 3 years employed, team becomes significant and remains important for the remainder of the journey. After 4 to 5 years in the organization, when the employee understands the industry, understands the organization and their job; growth becomes an important factor influencing engagement. For the group employees that are employed between 6 to 10 years, remuneration becomes important for engagement. When an employee is longer than 10 years within the company, team becomes again the most important factor for engagement.

Similar multi group analysis is done with seven groups, which represent the different departments: Coalition Rewards, Administration and Support, Cabin Crew, Commercial department, Operations department, Technical department and Flight Deck, since descriptive analytics showed large differences between departments regarding employee commitment and engagement.

\section{Evidence based recommendations for the company}

Since analyzing and modelling data provided more information from annual commitment survey than the diagnostic analysis which was done previously, the following evidence based recommendations for company management were provided.

As information, team and remuneration have the highest impact on engagement and commitment throughout the different departments and tenure groups, these topics should be the focus of HR. First of all, the company needs to target and increase the available information for employees. As information is identified as the most important factor influencing engagement, all efforts should be focussed on increasing the information flow and finding the most efficient ways how to ensure that employees obtain the necessary information for them. Thereby, employees specifically need more information with regards to the company's strategy for their engagement. Furthermore, employees feel rather unaware of the division of responsibilities within the organization which might be linked to departments acting as silos. Therefore, more effort should be taken to increase the linkages between departments, enabling employees with deeper insights into the division. Lastly, employees do not feel that they can give feedback in the organization, enabling horizontal and vertical dialogues can counteract these feelings. Secondly, as team is identified as a strong influence on engagement and commitment, HR needs to foster a good team atmosphere. Targeting remuneration is the third recommendation as it has a rather strong impact on commitment. Although increasing all wages is not realistic, the recommendation provided is to increase information given to the employees with regards to the adequacy of the remuneration compared to the market and to their job performance.

\section{Conclusion}

The added value of HR is often questioned due to the inability to show its impact on organizational performance in order to justify its activities. Although researchers have been studying this link between HR and organizational performance a few decades, still a lot is unknown. With the rise of EBM, HR Analytics evolved as a tool for HR to conduct EBM. However, only a few organizations 
have succeeded in implementing and using HR Analytics yet, because it is difficult to have the right competences, available resources and HR Analytics should be specifically tailored to the organization.

The researched case serves as evidence that predictive analytics provide focused evidence-based recommendations within the low available financial resources. What the entire organization needs in addition to the existing resources is knowledge and skills of an analyst and software. Analysing data with predictive methods, such as structural equation modelling (or regression analysis) allow organizations to gain much more valuable insights and make evidence based decisions.

\section{Acknowledgement}

This article has been elaborated as one of the outcomes of the "European Human Resource Management" project. Authors express gratitude to the students involved in the project: Alexandra Keunen, Radboud University, Dorien Van Boxel, Vlerick Business School, and Donovan Balducci EMLYON Business School.

\section{References}

Bassi, L. (2011). Raging debates in HR analytics. People and Strategy, 34(2), 14-18.

Boudreau, J. W., \& Ramstad, P. M. (2005). Talentship, talent segmentation, and sustainability: A new HR decision science paradigm for a new strategy definition. Human Resource Management, 44(2), 129-136.

Evans, W. R., \& Davis, W. D. (2005). High-performance work systems and organizational performance: The mediating role of internal social structure. Journal of Management, 31(5), 758-775.

Falletta, S. (2014). In search of HR intelligence: evidence-based HR analytics practices in high performing companies. People and Strategy, 36(4), 28-37.

Fink, A. A. (2010). New trends in human capital research and analytics. People and Strategy, 33(2), 14-21.

Fitz-enz, J. (1984). How to measure human resource management. New York, NY: McGraw-Hill.

Fitz-enz, J. (2010). HR Analytics: Predicting the Economic Value of Your Company's Human Capital Investments. New York, NY: AMACOM.

Fitz-Enz, J., \& John Mattox, I. I. (2014). Predictive analytics for human resources. Hoboken, NJ: John Wiley \& Sons.

Gardner, N., McGranahan, D., \& Wolf, W. (2011). Question for your HR chief: Are we using our 'people data' to create value? McKinsey Quarterly, 2, 117-121.

Hair, J.F., Ringle, C.M., Sarsdet, M. (2011). PLS-SEM: Indeed a silver bullet. Journal of Marketing theory and Practice, 19(2), 139-151.

Huselid, M. (1995). The impact of human resource management practices on turnover, productivity, and corporate financial performance. Academy of Management Journal, 38(3), 635-672.

Lawler III, E. E., Levenson, A. R., \& Boudreau, J. W. (2004). HR metrics and analytics: Use and impact. People and Strategy, 27(4), 27-35.

Mishra, S. N., Lama, D.R., \& Pal, Y. (2016). Human Resource Predictive Analytics (HRPA) for HR Management in Organizations. International Journal of Scientific \& Technology Research, 5(5), 33-35.

Mondore, S., Douthitt, S., \& Carson, M. (2011). Maximizing the impact and effectiveness of HR analytics to drive business outcomes. People and Strategy, 34(2), 20-27.

Paauwe, J., Guest, D., \& Wright, P. (2012). HRM \& Performance - Achievements \& Challenges. Chichester: John Wiley \& Sons Ltd.

Pease, G., Beresford, B., \& Walker, L. (2014). Developing human capital: Using analytics to plan and optimize your learning and development investments. Hoboken, NJ: John Wiley \& Sons.

Rasmussen, T., \& Ulrich, D. (2015). Learning from practice: how HR analytics avoids being a management fad. Organizational Dynamics, 44(3), 236-242.

Russel, C., \& Bennet, N. (2015). Big data and talent management: Using hard data to make the soft stuff easy. Business Horizons, 58(3), 237-242.

Rynes, S. L., Giluk, T. L., \& Brown, K. G. (2007). The very separate worlds of academic practitioner periodicals in human resource management: Implications for Evidence-Based Management. The Academy of Management Journal, 50(5), 9871008.

Suhr, D. (2006). The basics of structural equation modelling. Presented: Irvine, CA, SAS User Group of the Western Region of the United States (WUSS).

Van den Heuvel, S., \& Bondarouk, T. (2016, February). The Rise (and Fall) of HR Analytics. Proceedings from 2nd HR Division International Conference (HRIC), Sidney, Australia.

Verschuren, D.E. \& Doorewaard, H. (2010). Designing a research project (2nd edition). The Hague: Eleven International Publishing

Zainal, Z. (2007). Case study as a research method. Jurnal Kemanustaan, 9, Retrieved from http://psyking.net/htmlobj3837/case_study_as_a_research_method.pdf 